\title{
Reações da notícia do diagnóstico da síndrome de Down na percepção paterna
}

\author{
Down syndrome diagnosis news reactions in parents perception \\ Reacciones de la noticia del diagnóstico del síndrome de Down en la \\ percepción de los padres
}

\author{
Bruna Bianchi \\ Mestranda pela Universidade Federal São Carlos, São Carlos, SP, Brasil \\ E-mail: bruna_1996.b@hotmail.com ORCID: https://orcid.org/0000-0002-5289-7919 \\ Cariza de Cássia Spinazola \\ Professora doutora da Prefeitura Municipal de São Carlos, São Carlos, SP, Brasil \\ E-mail: carizaspinazola@gmail.com ORCID: https://orcid.org/0000-0001-5197-5834 \\ Márcia Duarte Galvani \\ Professora doutora da Universidade Federal São Carlos, São Carlos, SP, Brasil \\ E-mail: marciaduar@yahoo.com.br ORCID: https://orcid.org/0000-0003-1092-746X
}

Recebido em 22 de abril de 2019

Aprovado em 09 de março de 2021

Publicado em 23 de março de 2021

\section{RESUMO}

O nascimento de uma criança faz parte do ciclo de vida de uma família. Desde a sua concepção, a criança já é fruto de uma série de expectativas. $O$ objetivo desta pesquisa foi descrever e analisar as reações dos pais de crianças com síndrome de Down (SD) diante da notícia do diagnóstico da síndrome e os apoios recebidos para os cuidados do (a) filho (a). O delineamento da presente pesquisa foi de abordagem mista, de cunho descritivo. Foi utilizado para coleta dos dados: um roteiro semiestruturado de Entrevista de caracterização paterna. Participaram da pesquisa 10 pais (homens) de crianças diagnosticadas com SD na faixa etária de 0 a 6 anos de idade. $O$ contato com os pais ocorreu por meio de um Instituto de convivência de pessoas com SD em uma cidade do interior do estado de São Paulo. A coleta de dados com os pais ocorreu nas dependências do Instituto ou na residência dos próprios participantes. Foi realizada a análise de conteúdo com a categorização dos dados qualitativos das entrevistas. Os resultados apontaram que no quesito maneira como a notícia da SD foi dada, a maioria dos pais recebeu a notícia após o nascimento da criança. Em relação a mudanças na maneira como receberam a notícia, dois pais relataram que poderia ser diferente, os médicos poderiam ser mais sutis. Para o apoio para cuidados, nota-se que parte dos pais recebeu apoio pessoal e financeiro para os cuidados dos filhos. O estudo mostrou que o momento da notícia precisa ser reavaliado pelos profissionais, e que as intervenções devem focar nas crianças e nas famílias.

Palavras-chave: Educação Especial; Pais; síndrome de Down. 
http://dx.doi.org/10.5902/1984686X37804

\section{ABSTRACT}

The birth of a child is part of a family's life cycle. Since its conception, the child is already the result of a series of expectations. The aim of this research was to describe and analyze the reactions of parents of children with Down syndrome (DS) to the news of the diagnosis of the syndrome and the support received for the care of the child. The design of this research was a mixed approach of a descriptive nature. It was used for data collection: a semi-structured interview script with paternal characterization. Participated in the research 10 parents (men) of children diagnosed with DS in the age group from 0 to 6 years old. The contact with the parents took place through an Institute for the coexistence of people with DS in a city in the interior of the state of São Paulo. Data collection with parents took place on the premises of the Institute or at the residence of the participants themselves. Content analysis was performed with the categorization of qualitative data from the interviews. The results showed that in terms of how the news of DS was given, most parents received the news after the child's birth. Regarding changes in the way they received the news, two parents reported that it could be different, doctors could be more subtle. For support for care, it is noted that part of the parents received personal and financial support for the care of their children. The study showed that the moment of news needs to be reassessed by professionals, and that interventions should focus on children and families.

Keywords: Special Education; Parents; Down's syndrome.

\section{RESUMEN}

El nacimiento de un niño es parte del ciclo de vida de una familia. Desde su concepción, el niño ya es el resultado de una serie de expectativas. El objetivo de esta investigación fue describir y analizar las reacciones de los padres de niños con síndrome de Down (SD) a la noticia del diagnóstico del síndrome y el apoyo recibido para el cuidado del niño. El diseño de esta investigación fue un enfoque mixto de carácter descriptivo. Se utilizó para la recolección de datos: un guión de entrevista semiestructurado con caracterización paterna. Participaron en la investigación 10 padres (hombres) de niños diagnosticados con SD en el grupo de edad de 0 a 6 años. El contacto con los padres se realizó a través de un Instituto para la convivencia de personas con SD en una ciudad del interior del estado de São Paulo. La recogida de datos con los padres se llevó a cabo en las instalaciones del Instituto o en la residencia de los propios participantes. El análisis de contenido se realizó con la categorización de los datos cualitativos de las entrevistas. Los resultados mostraron que, en términos de cómo se dio la noticia del síndrome de Down, la mayoría de los padres recibieron la noticia después del nacimiento del niño. En cuanto a los cambios en la forma en que recibieron la noticia, dos padres informaron que podría ser diferente, los médicos podrían ser más sutiles. Para el apoyo al cuidado, se observa que parte de los padres recibió apoyo personal y económico para el cuidado de sus hijos. El estudio mostró que el momento de la noticia debe ser reevaluado por profesionales y que las intervenciones deben centrarse en los niños y las familias.

Palabras clave: Educación Especial; los padres; sindrome de Down. 
http://dx.doi.org/10.5902/1984686X37804

\section{Introdução}

A síndrome de Down (SD) é facilmente identificada no período imediato ao nascimento, por meio de algumas características peculiares. Algumas características fenotípicas das crianças com SD são: braquicefalia (cabeça achatada); fissuras palpebrais com inclinação superior; pregas epicânticas; base nasal achatada e hipoplasia da região mediana da face. O pescoço é mais curto, a língua é protusa e hipotônica, entre outras características (SILVA; DESSEN, 2002).

Atualmente, há o conhecimento desse diagnóstico logo no período gestacional, provenientes de exames mais precisos, que sugerem a suspeita da síndrome, a qual é confirmada pelo exame de cariótipo (CUNHA; BLASCOVI-ASSIS; FIAMENGHI JR, 2010).

De acordo com Cunha, Blascovi-assis e Fiamenghi Jr (2010), a notícia do diagnóstico de SD ou de qualquer outra deficiência para a família pode levá-los a passar por cinco estágios de impactos do diagnóstico. Vale ressaltar que alguns pais podem não passar por esses estágios, outros podem passar por alguns, assim como algumas mães passam por essas fases, porém não nessa ordem. O primeiro refere-se ao período de choque, comportamentos irracionais, com muito choro, sentimentos de desamparo e vontade de fugir. A segunda etapa corresponde à negação da anomalia de seus filhos. Na terceira acontecem reações emocionais dos pais, como, tristeza, raiva e ansiedade. O quarto estágio condiz com a adaptação, em que começa a aproximação afetivamente com o bebê. Já a quinta fase, diz respeito à reorganização familiar. No entanto, embora haja os sentimentos clássicos e a dificuldade em aceitar o diagnóstico do filho, perdura ainda a constante busca da cura da síndrome.

Segundo Vendrusculo (2014), entre o anúncio de uma gravidez até a chegada de um bebê, os pais idealizam uma série de planos para o bebê que está por vir, a fim de dar muitas oportunidades para a criança. Os planos vão desde oferecer diferentes brinquedos da última geração, roupas, o melhor colégio, viagens, curso de inglês, entre outros, como também planejam o futuro profissional do bebê e coisas que o mesmo deve ter e ser, segundo o desejo de seus pais.

Devido a este fato, o nascimento de uma criança com qualquer tipo de deficiência acarreta no planejamento dos pais uma divergência, necessitando ser reformulada, sendo importante reorganizar o espaço psíquico para acolher a criança que está por vir ou já está nos braços dos pais (VENDRUSCULO, 2014). 
http://dx.doi.org/10.5902/1984686X37804

Como relatado por Henn, Piccinini, Garcias (2008), o nascimento de uma criança com SD exigirá dos pais uma adaptação maior, pois estas crianças apresentam um atraso no desenvolvimento e algumas limitações em aquisições, necessitando assim de mais tempo para adquirir habilidades como andar, controlar os esfíncteres e na comunicação. Sendo assim, cada momento terá suas particularidades, o que algumas vezes pode acarretar em impactos sobre os genitores.

O médico é visto como o detentor de sabedoria e verdade universal, exercendo assim uma forte influência na maneira como os pais vão reagir frente à notícia sobre diagnóstico da síndrome de Down (OLIVEIRA, 2001). Algumas vezes, as atitudes dos pais frente a seus filhos são de se precipitarem por eles, tomarem seus lugares, por explicitarem uma intensa preocupação com o bem estar deles, com o desejo de defendê-los da sociedade cruel para as pessoas com deficiências, o que pode acarretar em uma dificuldade de aquisição de certas individualidades e habilidades. Entretanto, em muitos casos, os pais conseguem proporcionar aos filhos possibilidades de desenvolvimento enquanto seres humanos capazes de aprendizado e individualidade (SOUZA; BOEMER, 2003).

Segundo Vendrusculo (2014), à medida que a deficiência do filho se torna mais familiar, os pais conseguem ter uma elaboração psíquica. No lugar das resistências encontradas no primeiro momento, deve-se colocar o conhecimento da deficiência, transformando-as em novas experiências.

A partir do momento que os pais criam novas experiências para estimular seu filho com deficiência é que este consegue se desenvolver melhor, pois mesmo que um filho não tenha nenhuma deficiência, em um ambiente empobrecido de estímulos, a criança não conseguirá se desenvolver plenamente. $O$ desenvolvimento da inteligência de toda e qualquer criança, com ou sem deficiência necessita de muitos estímulos, ou seja, submeter uma criança a estímulos pobres ou até mesmo a falta deles, faz com que haja uma barreira nas chances de desenvolvimento desta criança (VENDRUSCULO, 2014).

Desde os primeiros dias de vida, o trabalho dos pais com seu filho deve se dar por meio da estimulação precoce ${ }^{1}$, com o intuito de auxiliar a família e a criança no desenvolvimento, sendo que as interações se dão por meios instrumentais como: psicomotricidade, linguagem, aprendizagem, hábitos de vida, socialização e o brincar (VENDRUSCULO, 2014).

Segundo Dessen e Braz (2000) com a chegada de um bebê com deficiência, a família acaba se reestruturando, havendo a necessidade de um equilíbrio entre os responsáveis para lidar com as novas situações que surgem nesses períodos, principalmente a contribuição do 
http://dx.doi.org/10.5902/1984686X37804

pai para o desenvolvimento do seu filho. Sendo assim, cada vez mais têm surgido estudos e pesquisas visando identificar a figura masculina dentro da estrutura familiar, a fim de contribuir para o conhecimento e entendimento desse contexto.

Segundo Silva e Aiello (2009), estudos recentes apontam para a presença do pai biológico ou até mesmo da figura masculina dentro da estrutura familiar como um fator fundamental para o desenvolvimento das crianças.

O papel do pai vem se alterando na sociedade, devido às transformações culturais, sociais e familiares, indo da fase de que os filhos eram propriedades do pai, com a mãe sem direito, até na fase em que o pai era apenas um suporte econômico da família (BENCZIK, 2011).

De acordo com Silva e Aiello (2009), o pai deixou de ser apenas o mantenedor da família, para ser um fator importante no desenvolvimento psicoafetivo de seu filho, por meio de afetos e atitudes, além de se constituir como referência para a personalidade da criança e o transmissor da autoridade social, o pai é um ser de autoridade, segurança, ideais e valores (SILVA; AIELLO, 2009).

Segundo Benczik (2011), o pai é muito importante no desenvolvimento da criança, podendo ser melhor a relação entre pai e filho, caso o pai participe ativamente do crescimento e educação da criança. Lamb (1997) coloca que os pais que estão mais altamente envolvidos com suas crianças, podem influenciar uma maior competência cognitiva, menor crença sexualmente estereotipada, maior empatia e um maior nível de controle interno.

Devido às mudanças no papel do pai que ocorreram na estrutura familiar, Lamb e colaboradores (1985) definem o envolvimento paterno a partir de três dimensões de avaliação do seu comportamento: interação, acessibilidade à criança e responsabilidade. A primeira diz respeito ao contato direto com o filho, em atividades compartilhadas e cuidados; a segunda refere-se à presença ou disponibilidade para a criança para possíveis interações e, por último, a responsabilidade corresponde ao papel do pai em garantir cuidados e recursos para seu filho.

Mondardo e Valentina (1998) especificam que atualmente os pais dividem os trabalhos com suas companheiras, indo às reuniões, levando os filhos ao dentista, pediatra, dança, futebol, ou até mesmo ficam em casa quando seu filho encontra-se doente, sendo assim, pode-se confirmar que a presença de um pai é tão fundamental quanto a da mãe, quando pensa-se no desenvolvimento socioemocional da criança. O ideal seria que o pai colaborasse ativamente desde o nascimento de seu filho, participando dos momentos de banho, conversa 
com pediatra e enfermeiras, troca de fralda, cantigas. Mesmo se o casal estivesse separado, é de suma importância que o pai participe com a mãe dos questionamentos sobre as preferências de seu filho, para assim fazer parte da vida dele.

Para Benczik (2011), as famílias mudaram o foco do modelo tradicional, atualmente ao papel de autoridade do pai, é adicionado o papel de fornecedor de carinho, tornando-se mais ativo na vida da criança, brincando e atuando na formação e educação dela.

Lamb e Billings (1997) colocam que sempre foi dada muita atenção no papel da mãe, mas que pouco se sabe sobre como e quanto os pais - homens - gastam seu tempo com seus filhos com deficiência e mesmo que nos últimos anos tenham estudos sobre o papel do pai em diversos contextos, estes acabam por não abordar a paternidade com crianças com deficiência intelectual. Além disso, os estudos existentes apresentam, muitas vezes, limitações, pois os dados baseiam-se em dados clínicos, relatórios maternos a respeito das reações emocionais e comportamentais dos pais.

Nessa perspectiva, ao considerar que os estudos baseiam-se em dados clínicos e relatos maternos a respeito das reações emocionais e comportamentais dos pais, cabem os seguintes questionamentos: (a) quais são as reações dos pais diante da notícia de ter um filho com SD? (b) como os mesmos se fazem presentes na vida de seus filhos? (c) quais apoios recebem durante a notícia e depois para os cuidados da criança?

\section{Objetivo}

Descrever e analisar as reações dos pais (homens) de crianças com SD diante da notícia do diagnóstico da deficiência e apoios recebidos para os cuidados do (a) filho (a).

\section{Método}

\section{Delineamento}

O delineamento da presente pesquisa foi com abordagem mista de cunho descritivo.

\section{Procedimentos éticos}

O projeto de pesquisa foi submetido à avaliação do Comitê de Ética em Pesquisa de Seres Humanos da Universidade Federal de São Carlos (CAEE: 81125417.8.0000.5504) e após aprovação os participantes foram recrutados de acordo com o interesse em participar da pesquisa. 
http://dx.doi.org/10.5902/1984686X37804

\section{Participantes}

Participaram do estudo dez pais, todos casados, com uma média de idade de 39,1 anos, desses, apenas quatro não participavam de um grupo de apoio a pais.

A Tabela 1 se refere à caracterização dos participantes. Os pais desta pesquisa foram nomeados por $\mathrm{P} 1$ até $\mathrm{P} 10$, correspondente ao número total de participantes.

Tabela 1 - Caracterização dos participantes

\begin{tabular}{|c|c|c|c|c|c|c|}
\hline Participantes & Idade & $\begin{array}{c}\text { Status } \\
\text { Conjugal }\end{array}$ & Escolaridade & Profissional & $\begin{array}{c}\text { Renda } \\
\text { familiar } \\
\text { anual }\end{array}$ & $\begin{array}{c}\text { Pertence a } \\
\text { um grupo } \\
\text { de apoio a } \\
\text { pais }\end{array}$ \\
\hline P1 & 34 & Casado & $\begin{array}{l}\text { Cursando } \\
\text { superior }\end{array}$ & $\begin{array}{l}\text { Inspetor de } \\
\text { manutenção }\end{array}$ & 40.000 & Sim \\
\hline P2 & 43 & Casado & $\begin{array}{l}\text { Segundo } \\
\text { grau } \\
\text { completo }\end{array}$ & $\begin{array}{l}\text { Técnico em } \\
\text { telefonia }\end{array}$ & 15.000 & Sim \\
\hline P3 & 41 & Casado & $\begin{array}{l}\text { Superior } \\
\text { completo }\end{array}$ & Administrador & 72.000 & Sim \\
\hline P4 & 39 & Casado & $\begin{array}{l}\text { Superior } \\
\text { completo }\end{array}$ & Empresário & 70.000 & Sim \\
\hline P5 & 35 & Casado & $\begin{array}{l}\text { Ensino médio } \\
\text { completo }\end{array}$ & Entregador & 30.000 & Não \\
\hline P6 & 39 & Casado & $\begin{array}{l}\text { Segundo } \\
\text { grau } \\
\text { completo }\end{array}$ & Serralheiro & 20.000 & Sim \\
\hline P7 & 52 & Casado & $\begin{array}{l}\text { Superior } \\
\text { completo }\end{array}$ & $\begin{array}{l}\text { Servidor } \\
\text { público }\end{array}$ & 109.000 & Não \\
\hline P8 & 29 & Casado & $\begin{array}{l}\text { Segundo } \\
\text { grau } \\
\text { completo }\end{array}$ & $\begin{array}{c}\text { Vigilante } \\
\text { patrimonial }\end{array}$ & 18.000 & Não \\
\hline P9 & 42 & Casado & $\begin{array}{l}\text { Segundo } \\
\text { grau } \\
\text { completo }\end{array}$ & Vendedor & 48.000 & Não \\
\hline P10 & 37 & Casado & $\begin{array}{l}\text { Superior } \\
\text { completo }\end{array}$ & $\begin{array}{c}\text { Representante } \\
\text { comercial }\end{array}$ & 48.000 & Sim \\
\hline
\end{tabular}

Fonte: elaborado pelas autoras (2018). 
http://dx.doi.org/10.5902/1984686X37804

A Tabela 2 se refere à caracterização dos filhos dos participantes. Os filhos dos participantes foram nomeados nessa pesquisa por $\mathrm{C} 1$ até $\mathrm{C} 10$, correspondente ao número pelo qual o pai foi nomeado, ou seja, a criança nomeada por C1 é filho (a) do pai nomeado por P1 e assim por diante.

Tabela 2 - Caracterização dos filhos (as) participantes

\begin{tabular}{cccc}
\hline $\begin{array}{c}\text { Identificação da } \\
\text { criança }\end{array}$ & Idade da criança & Sexo da criança & $\begin{array}{c}\text { Escolaridade da } \\
\text { criança }\end{array}$ \\
\hline C1 & 5 & Feminino & Educação Infantil \\
\hline C2 & 3 & Masculino & Educação Infantil \\
\hline C3 & 4 & Masculino & Educação Infantil \\
\hline C4 & 6 & Feminino & Educação Infantil \\
\hline C5 & 5 & Feminino & Educação Infantil \\
\hline C6 & 2 & Feminino & Não vai à escola \\
\hline C7 & 5 & Masculino & Educação Infantil \\
\hline C8 & 6 & Feminino & Educação Infantil \\
C9 & 7 & Masculino & Ensino Fundamental \\
\hline C10 & 6 & Feminino & Educação Infantil \\
\hline
\end{tabular}

Fonte: elaborado pelas autoras (2018).

\section{Local}

O contato com os pais ocorreu por meio de um Instituto de convivência de pessoas com síndrome de Down, em uma cidade do interior de São Paulo. A coleta de dados com os pais ocorreu nas dependências do Instituto e na residência dos próprios participantes.

\section{Materiais e equipamentos}

Foram utilizados os seguintes materiais e equipamentos: papel sulfite, impressora, computador portátil, caneta e gravadores.

\section{Instrumento para coleta de dados}

Roteiro semiestruturado de Entrevista: o roteiro foi construído pela pesquisadora e avaliado por três juízes, que eram pesquisadores do Programa de Pós-Graduação em educação especial. O roteiro continha 09 questões abertas divididas em 04 temáticas, sendo eles: (1) Sentimentos e reações frente ao diagnóstico da SD; (2) Conhecimento sobre 
http://dx.doi.org/10.5902/1984686X37804

a síndrome de Down; (3) Apoios recebidos para os cuidados do filho; (4) Expectativas paternas em relação à educação do (a) filho (a) com síndrome de Down.

\section{Procedimentos de coleta de dados}

A pesquisadora entrou em contato com um instituto de convivência de pessoas com $\mathrm{SD}$, para explicar os objetivos da pesquisa e os procedimentos da coleta de dados. Após o consentimento da coordenadora de projetos do Instituto, foi estabelecido um contato via telefonema com os pais das crianças alvos, a fim de explicar os objetivos da pesquisa e de os mesmos assinarem o Termo de Consentimento Livre e Esclarecido. Após combinar o local e horário da entrevista, os pais responderam ao instrumento. $O$ instrumento foi preenchido em forma de entrevista. Os encontros com os pais duravam em média uma hora. A pesquisadora perguntava ao pai se podia gravar em áudio a entrevista, para depois transcrever, ou seja, com o consentimento dos pais, todas as entrevistas foram gravadas. Alguns encontros aconteceram na residência dos participantes e outros ocorreram na sede do grupo de apoio.

\section{Procedimentos de análise dos dados}

Os dados qualitativos obtidos nas entrevistas com os pais foram analisados de forma descritiva. Foi realizada a análise de conteúdo com a categorização dos dados qualitativos das entrevistas. A categorização é "uma operação de classificação de elementos constitutivos de um conjunto, por diferenciação seguida de um reagrupamento baseado em analogias, a partir de critérios definidos" (FRANCO, 2008. p.59). Sendo assim, as categorias foram: maneira como a notícia da SD foi dada; mudanças na maneira como receberam a notícia da SD; conhecimentos atuais sobre a SD; adaptação da dinâmica da família ao nascimento da criança com SD; apoio para cuidados; apoio recebido no momento da notícia; e sugestões aos profissionais no momento da notícia aos pais.

\section{Resultados e Discussão}

Descrição e análise das reações dos pais diante da notícia da SD e apoios recebidos

Em relação à maneira como a notícia da SD foi dada identificou-se que para $\mathrm{P} 1$, P2, P3, P4, P5, P6, P7, P8 e P10 a notícia foi após o nascimento: 
http://dx.doi.org/10.5902/1984686X37804

Para falar a verdade, foi para mim primeiro...perguntaram, você que é o pai da criança? Sim sou eu, ai ele disse, a então sua filha nasceu com um probleminha, ai tinha alguma coisa que parece que me avisou, sua filha nasceu com síndrome de Down...o médico disse que a minha filha tinha nascido com sopro no coração...ela também nasceu com síndrome de Down (P1).

Ela veio falando, olha seu filho tem Down, ele vai fazer o que todos fazem, correr, brincar, mas vai ser um pouco mais lento (P2).

[...] ele estava olhando uma criança que estava ao lado e ai o pediatra de plantão, que não era o dele, desconfiou pelos traços...o geneticista olhando do lado, disse essa criança tem síndrome de Down. Deu a notícia para a minha esposa que estava no quarto e depois para mim (P3).

Foi complicado viu, a gente ficou sabendo na hora, não foi nada antes...mas para mim foi mais fácil do que para a minha esposa, eu resolvi um pouco mais fácil, ela demorou um pouco para assimilar (P4).

Foi surpresa, porque nós fizemos todos os exames e nada constava... a médica veio e me falou assim, olha pai ela nasceu bem, mas nós suspeitamos que ela tenha alguma síndrome, como ela nasceu com essas coisas (uma parte do rosto roxo), vamos avaliar...a médica disse que estavam suspeitando de síndrome de Down, por causa da orelhinha, dos traços, mas que isso só seria verificado com o cariótipo...no exame constou a SD (P5).

Na verdade, a notícia foi dada pela minha mulher, pelo telefone. Ela estava na gota e ela tinha tido o parto, eu estava com os amigos, indo para lá e foi ai que ela me contou... O médico simplesmente falou para ela, sua filha tem síndrome de Down e pronto, curto e grosso (P6).

No parto, o pediatra que era da minha mulher, me chamou e disse para consultar um especialista em síndromes, por causa de algumas características dele, mão, pé, rosto, entre outras (P7).

Fui chamado lá pela pediatra...foi passado a informação pra mim, pela aparência, pelo rosto, mãos, pés, falou que ela simplesmente poderia ter síndrome de Down, que ai ela iria fazer os exames complementares com o geneticista para comprovar isso ai (P8).

A notícia foi dada na hora do parto (P10).

Os relatos apontaram que para a maioria dos participantes, a notícia do diagnóstico foi dada, após o nascimento da criança.

A síndrome de Down é facilmente detectada no período imediato ao nascimento, por causa das características específicas, assim sendo, a notícia é transmitida aos genitores ao nascimento (CUNHA; BLASCOVI-ASSIS; FIAMENGHI JR, 2010). O momento da notícia sempre será um episódio difícil para os pais.

Segundo Brandão (2017), a grande insatisfação por parte das famílias é o modo como a notícia é dada, e provavelmente que esses sentimentos de tristeza, raiva, susto, sejam desencadeados a partir do modo como a notícia foi dada pelos profissionais de saúde. 
Deve-se considerar que, muitas vezes, as informações transmitidas pelos profissionais aos pais da criança, podem ser distorcidas de acordo com o choque sentido por eles (KOZMA, 2007).

Embora muitas mulheres neguem os sentimentos ao nascimento de um filho com SD, o tão chamado "luto pelo filho imaginado" é sentido pela grande maioria das famílias que tem um filho com deficiência (XAVIER, 2017).

Conforme Chacon (2011) aponta, os pais apresentam diferenças no momento em que se dão conta da deficiência do filho, estando relacionado ao modo como aceitam a informação que estão tendo no momento da notícia, principalmente em relação às necessidades do filho.

Em contrapartida, para P9 a notícia foi dada durante a gestação da esposa, conforme fala ilustrativa:

Quanto a notícia da síndrome, a gente recebeu no ultrassom...O médico conversou com a minha esposa, falou que havia dado uma alteração na nuca (P9).

O diagnóstico vem sendo mais frequente ainda no período gestacional, por meio de exames que estão cada vez mais precisos e que levantam suspeitas que são confirmadas por meio do exame de cariótipo (CUNHA; BLASCOVI-ASSIS; FIAMENGHI JR, 2010).

O momento da notícia de ter um filho com SD é crucial, pois a forma como esta é dada, a linguagem utilizada, podem dificultar ou facilitar a compreensão dos pais em relação aos aspectos clínicos, influenciando nas expectativas, no que se refere ao desenvolvimento físico, intelectual e emocional do filho, o que pode interferir no vínculo afetivo estabelecido entre pais e filhos (BRANDÃO, 2017).

A notícia do diagnóstico de uma criança com deficiência causam, nos pais e nas mães, questões emocionais, fazendo-os passar por difíceis períodos, relacionados com a criança (BRITO; DESSEN, 1999). Como no caso do P.4, em que relatou que para ele foi mais fácil lidar com a notícia do diagnóstico do que para a sua esposa, pois esta demorou em assimilar o que estava acontecendo.

\section{Quando questionados sobre se mudariam algo na maneira em que receberam a} notícia da SD do filho (a) P1, P2, P4, P5, P6, P7 e P8 não mudariam nada.

Olha eu não mudaria nada não, por que acho que do jeito que aconteceu foi a melhor forma...já que você recebe a notícia na hora, você começa a se preparar ali, não antes (P1). 
http://dx.doi.org/10.5902/1984686X37804

Nada, que nem eu falei, eu recebi, pra mim foi normal. Ela foi direta, ela chegou e falou, seu filho tem Down, vai aprender, vai andar, vai fazer tudo, só que vai demorar, vai ter que dar mais tempo (P2).

Eu acho que não mudaria, porque se a gente soubesse antes ia ser pior, a minha esposa ia pirar, a gravidez não ia decorrer como foi...se fosse só eu, eu preferiria saber antes (P4).

Sem problema no coração, nada, não mudaria nada (P5).

Nada e agradeço do médico no parto...Eu acho que foi melhor ficar sabendo depois, porque é um sofrimento que a gente tem, porque não sabemos como vai ser, o que vai ser, de que jeito, a gente só vai imaginar o pior né, então realmente eu acho que não saber e ficar sabendo apenas na hora é a melhor coisa (P6).

Mudaria nada (P7).

Nada, saber em cima da hora ajudou o crescimento tanto meu, quanto da minha esposa, da forma de eu correr atrás, um incentivo a mais, um impulso vamos dizer assim, de saber um pouco mais de uma criança com síndrome de Down, as necessidades (P8).

A notícia influencia não somente na imagem que os pais vão ter da criança e do seu futuro, mas também, o futuro de toda a família. Por isso, é muito importante que seja proporcionado aos pais um processo de adaptação, com informações mais claras, que façam com que os mesmos se sintam mais acolhidos e satisfeitos e apresentem uma menor frustação (BRANDÃO, 2017). Receber a notícia que terá um filho com SD durante a gestação, poderia ajudar os pais a se prepararem melhor para os cuidados da criança que está por vir e a entender um pouco mais sobre SD.

Mesmo os pais apontando que foi difícil e uma surpresa, os mesmos não mudariam a maneira como a notícia foi dada, este fato pode ter relação com a idade das crianças, pois já passaram um tempo desde o nascimento e os sentimentos do momento da notícia já foram superados.

O participante P3 não respondeu se mudaria algo na maneira como recebeu a notícia de ter um filho (a) com SD, voltando sua reflexão para a visão médica, compreendendo que a notícia em si gera um grande impacto nos familiares, independente da forma como for dada

Difícil, eu já me fiz essa pergunta, mas é que eu vou voltar para os lados dos médicos...nós dissemos que os médicos são frios, mas infelizmente não é, eu vejo que é tão difícil para eles darem a notícia, quanto para nós que vamos receber, ele não pode se derrubar na frente do paciente, porque ai ele pode colocar tudo a perder (P3). 
Para o médico, dar a notícia de uma criança com SD pode não ser uma tarefa fácil. Para Brandão (2017), muitos profissionais da saúde relatam que nunca tiveram treinamentos sobre como dar essa notícia aos familiares com mais sensibilidade, de modo com que os familiares se sintam satisfeitos com as informações recebidas, e ao mesmo tempo se sintam acolhidos diante da nova realidade. Segundo Brandão (2017), os profissionais evidenciam também que se sentem despreparados, ansiosos e que apresentam sentimento de impotência ao dar a notícia aos familiares.

Para P9 a maneira como a notícia de ter um filho (a) com SD foi dada poderia ser mais sutil.

Eu acho que o médico poderia ser mais sutil, talvez pudesse ser mais preparado né. Foi meio de supetão (P9).

Para P10 a maneira como a notícia de ter um filho (a) com SD foi dada poderia ser durante a gestação.

Gostaria de ter ficado sabendo durante a gravidez, para pode me preparar para o momento (P10).

Os relatos apontaram que para os dois participantes, P9 e P10, a maneira como a notícia foi dada poderia ser diferente, por exemplo, o médico poderia ser mais preparado para este momento da notícia e que gostariam de receber esta durante a gravidez para conseguirem se preparar melhor.

No entanto, não é possível saber se receber a notícia durante a gravidez, ou após o nascimento da criança, seria a melhor opção, pois poderia desencadear desconforto, depressão, entre outros sentimentos, pelo fato de que toda a expectativa de ter um bebê saudável seria quebrada.

Segundo Silva e Dessen (2002) a principal queixa dos pais de crianças com SD é a forma como os médicos dão a notícia do diagnóstico, pois muitas vezes essas acabam favorecendo a incredulidade da síndrome.

Constantemente, a maneira como a notícia é transmitida aos pais é de forma inadequada, o que causa maior sofrimento, fazendo com que os pais tenham uma maior dificuldade em aceitar o filho (CUNHA; BLASCOVI-ASSIS; FIAMENGHI JR, 2010).

É importante que os profissionais tenham uma linguagem mais adequada no momento da notícia, a fim de transmitir aos pais informações mais claras, objetivas e atualizadas (CUNHA; BLASCOVI-ASSIS; FIAMENGHI JR, 2010). 
http://dx.doi.org/10.5902/1984686X37804

Dando continuidade nessas questões, na categoria conhecimentos atuais sobre a SD, para P1, P2, P3, P4, P6, P8, P9 e P10 estes conhecimentos aumentaram após o nascimento do (a) filho (a)

Aumentou muito, antes eu não sabia nada né, ia pesquisar para que né? (P1)

O conhecimento, eu sabia sobre a deficiência, eu tinha um pouco, hoje eu participo daqui do grupo, as vezes vejo algo na internet, mas nada demais (P2).

Então, naquele momento, nós não sabíamos nada sobre a $S D$, a gente começou a se aprofundar depois da notícia, começamos a entender o que era a $S D(P 3)$.

Eu tenho trezentas vezes mais, eu tenho até um primo na família, sabia da $S D$, as coisas bem básicas, hoje eu dou aula (P4).

A com certeza aumentaram bastante. Eu conhecia muito pouco...mas pra ser sincero, eu nunca me aprofundei em estudos mesmo, porque eu não tenho a prática de estudar, minha mulher sabe mais, eu sei mais por conversar, bater papo (P6).

No segundo colegial eu tive um pouco de contato com algumas síndromes por uma peça de teatro...mas eu fui ter mesmo um contato e buscar coisas depois dela (P8).

Quando a gente soube da notícia, nós não tínhamos contato com nenhuma criança né...A gente não conhecia, não sabia das capacidades, das limitações...Hoje não, hoje nós sabemos da capacidade dele (P9).

Pesquisamos muito (P10).

Alguns pais buscaram mais informações sobre a SD do que outros pais, alguns até deixaram para a esposa pesquisar.

Percebeu-se que o envolvimento do pai pode ser impulsionado em direção à construção do conhecimento sobre a deficiência do filho, fazendo com que ele consiga desenvolver estratégias que ajudem a gerenciar as demandas e potencialidades da criança. No entanto, para que isso ocorra, é necessário que o pai tenha participação ativa no trabalho de intervenção com seu filho (GOITEIN; CIA, 2011). Quanto maior os conhecimentos e habilidades que os pais adquirem, mais conseguirão lidar com os desafios que apareceram em relação ao filho, favorecendo o processo de aceitação (GLAT, 1996).

De acordo com Bronfenbrenner (2011), quanto maior for o conhecimento dos pais, maior a probabilidade que eles têm de manter boas relações com os seus filhos.

Apenas os pais P5 e P7 já conheciam alguém com SD antes do nascimento do filho (a). 
http://dx.doi.org/10.5902/1984686X37804

Para mim, eu já conhecia crianças com SD...(P5)

Conhecia uma pessoa com síndrome de Down, não tinha nenhum parentesco, mas era bem próximo (P7).

Nota-se que mesmo que os pais tenham os mesmos conhecimentos que antes do nascimento de seus filhos com síndrome de Down, é de suma importância que sempre busquem por mais informações ao longo das fases de desenvolvimento das crianças.

No que se refere à adaptação da dinâmica da família ao nascimento da criança com SD, P1, P4, P5, P6, P7, P8, P9 e P10 relataram algumas mudanças

Não, acho que não, vida normal. A única adaptação que teve, é que minha esposa voltou a trabalhar agora (P1).

Foi tranquila até...fomos aprendendo o que a gente tinha que fazer com ela e fomos tocando a vida (P4).

Minha mulher parou de trabalhar...eu pensei, se minha mulher vai sair para ganhar um pouco de dinheiro, deixa que esse pouco eu ganho e você cuida das crianças, porque a gente que tem, já sabe cuidar pouco, os outros menos ainda (P5).

Sim teve, minha mulher parou de trabalhar para ficar com ela. Eu realmente trabalhava em um horário e hoje eu não trabalho mais de manhã para fazer as fisioterapias para ela (P6).

[...] minha mulher parou de trabalhar para ficar com ele (P7).

Um pouco, existia um pouco de não conhecimento do que era a síndrome de Down, ninguém conhecia, ninguém sabia, porque a gente não tem caso na família, então a gente não sabia exatamente o que era, então a família ficou um pouco apreensiva (P8).

Tiveram várias mudanças... o fato de ter que levar ele na USE, na Federal, de ter o estímulo desde os dois meses né....sim, bastante, essa rotina que a gente tinha antes de ter um filho e depois mudou muito. O que os fisioterapeutas faziam de exercício, nós tentávamos fazer em casa de estimulação (P9).

Foi difícil, principalmente nos primeiros meses, mas depois tudo vai entrando nos eixos (P10).

De forma natural, o nascimento de um bebê já acarreta mudanças e reestruturação de papéis de uma família (BRADT, 1995) e quando se trata do nascimento de uma criança com síndrome de Down, o processo de adaptação por parte dos pais pode ser maior, pois o filho apresenta atraso em seu desenvolvimento e limitações em suas aquisições, havendo a necessidade de um tempo maior para desenvolver habilidades como, andar, falar, etc (KOZMA, 2007).

Segundo Henn, Piccinini e Garcias (2008), os pais de crianças com SD apresentavam menores níveis de estresse do que as mães. E algumas dificuldades foram destacadas como, 
questões financeiras, planejamento familiar, preocupações de longo prazo para com seus filhos e restrições familiares, no entanto, os pais demonstraram uma visão positiva da personalidade de seus filhos, uma boa adaptação às exigências e cuidados demandados por eles.

Segundo Saladini, Cia e Fantinato (2011), o nascimento de uma criança com deficiência acarreta algumas mudanças na vida dos genitores, pois a partir desse momento, começam a se preocupar com o filho e realizam mudanças em suas rotinas em decorrência da criança.

De acordo com Xavier (2017), o convívio familiar pode deixar de ser um momento harmonioso e lúdico e passa a ser uma lista de exercícios a serem feitos visando o desenvolvimento da criança com SD. A sala de estar se transforma em sala de fisioterapia, a hora de comer passar a ser um momento de fortalecimento da musculatura bucofacial, a hora de vestir torna-se um momento de repetições. Tudo o que se faz, tem a ver com esperar a melhora na condição da criança com SD.

Em um ambiente em que há uma criança com deficiência é imprescindível que os cuidados sejam compartilhados, ambos, pai e mãe, devem dividir as tarefas que vão desde o cuidado com a casa, os outros filhos ao acompanhamento da díade mãe-bebê, as consultas médicas e terapêuticas, e apoio emocional e incondicional que devem ser dados a cada membro familiar que participa dessa nova adaptação de ter uma criança com deficiência (XAVIER, 2017).

De acordo com Martins e Pires (2008), normalmente são as mães, em famílias no qual há filhos público alvo da educação especial, que assumem a responsabilidade pelos cuidados do filho, havendo a necessidade, muitas vezes, de deixar o trabalho e as atividades pessoais, a fim de se dedicar totalmente ao filho, como vimos na presente amostra. Os dados dessa pesquisa apontam consonância com os dados indicados neste estudo, pois muitas mães deixaram de trabalhar para cuidar dos filhos, enquanto os pais apresentam o papel de mantenedor financeiro.

Para P2 e P3 não houve mudanças na dinâmica da família após o nascimento do (a) filho (a) com SD

Nada, tanto que a gente o colocou na escolinha, porque eu e minha esposa trabalhamos (P2).

Nenhuma...o tratamento é normal, tanto para ele, quanto para minha outra filha (P3). 
http://dx.doi.org/10.5902/1984686X37804

As interações dentro do núcleo familiar são as que trazem mais significados para o desenvolvimento da criança, a inclusão começa no leito da maternidade (XAVIER, 2017).

Em relação ao apoio para cuidados com o (a) filho (a) com SD, P1, P2, P5, P6 e P7 disseram receber apoio.

Sim...tem o CEDIP (Centro de Especialidade de Reabilitação) aqui na cidade, quando nasce criança prematura ou com alguma síndrome, eles já encaminham direto pra lá. E lá tem os profissionais né, tem T.O., tem psicóloga, tem fonoaudióloga (P1).

Sim recebi e continuo recebendo (P2).

Financeiramente minha mulher recebe um salário, mas não pode trabalhar (P5).

A gente recebe sim um auxílio do governo...acho que é um salário...eu e nem minha mulher podemos ser registrados (P6).

Recebo apoio da UFSCar, a USE e da APAE (P7).

Nota-se que parte dos pais recebeu apoio pessoal para os cuidados do filho, como do CEDIP, da Universidade Federal de São Carlos, da instituição, apoios financeiros através do governo. Muitas famílias que têm um filho do PAEE necessitam de apoio financeiro para conseguir suprir as necessidades do filho (NARVAZ; KOLLEER, 2004).

Os programas de apoios oferecidos aos familiares devem ser pensados a fim de atender as necessidades que os pais apresentam em cada momento. A mulher gestante necessita de apoios para o enfrentamento desse período até o nascimento, já para a família, que recebe a notícia após a chegada da criança, deve ser orientada e apoiada para cuidar do bebê e buscar o tratamento mais adequado (CUNHA; BLASCOVI-ASSIS; FIAMENGHI JR, 2010).

Em contrapartida, os participantes $\mathrm{P} 3, \mathrm{P} 4, \mathrm{P} 8, \mathrm{P} 9$ e $\mathrm{P} 10$ relataram não receberem apoios financeiros

Eu não recebo nada de ajuda, de custo, eu não recebo nada pelo meu filho (P3).

Em relação ao apoio emocional, a gente recebeu apoio com os cuidados da nossa filha dos familiares...Mas apoio financeiro não, porque a gente não necessitou (P4).

A gente não recebe apoio nenhum, não recebemos apoio nenhum em questão financeira (P8).

Não, não recebo nenhum apoio...Nós estávamos até tentando entrar com advogado para ver o direito que ele tem, porque eu não sei se é verdade, que ele tem direito a ajuda mensal. A gente sabe que ele tem o direito de usar o adesivo de vaga especial no carro, mas nós não recebemos e não contamos com nenhum apoio (P9).

Apoio do governo? Não (P10). 
http://dx.doi.org/10.5902/1984686X37804

Estudos de Gualda, Borges, Cia (2013) e Spinazola (2014) vem demostrando que as necessidades financeiras, são apontadas por famílias de crianças PAEE, principalmente no que tange ao pagamento de despesas com terapias, cuidados médicos, tratamentos e ajudas técnicas com relação a equipamentos. Estes estudos indicam que assim como a área emocional e financeira também precisa ser repensada diante da nova realidade.

No que se refere ao apoio recebido no momento da notícia, P1, P2, P4, P8, P9 e P10 relataram que receberam algum tipo de ajuda, como pode ser identificado a seguir

Apoio dos profissionais da saúde, a gente não teve nenhum. O único apoio que nós tivemos no ato da notícia foi só dos familiares...de resto nenhum, nem de psicóloga, nem nada (P1).

Apoio motivacional só (P2).

[...] a gente teve esse apoio tanto da família, quanto dos amigos (P4).

No momento de receber a notícia dela, eu recebi somente as orientações de procurar um geneticista e quais procedimentos tomar para ela (P8).

No momento da notícia, o apoio que a gente teve foi o meu para a minha esposa e o da minha esposa comigo...e o apoio dos nossos familiares (P9).

No momento da notícia o apoio foi da família (P10).

Segundo relato dos pais, não houve um apoio de equipe da área da saúde. Nesse quesito, destaca-se a importância do apoio de uma equipe multiprofissional, como o psicólogo, por exemplo, no momento de dar a notícia do diagnóstico aos genitores, sendo esse apoio elaborado com base nas interações familiares, o que facilitaria a integração da criança na família (SILVA; DESSEN, 2002).

Conforme Salomão (1985) aponta, o apoio familiar, principalmente aquele advindo do marido, em famílias com crianças do PAEE, é de suma importância para ajudar a mãe a aceitar e a conviver com o filho com deficiência. Como pode ser observado no caso do P9, que salientou esse apoio mútuo entre o casal.

O estudo de Gualda (2015) realizado com famílias de crianças público alvo da educação especial em idade pré-escolar identificou, por meio da escala de suporte social, que o cônjuge, os pais, filhos e irmãos e amigos foram os mais mencionados pelas famílias, como fonte de apoio.

Porém, os participantes $\mathrm{P} 3, \mathrm{P} 5, \mathrm{P} 6$ e $\mathrm{P} 7$ relataram não terem recebido nenhum tipo de apoio durante a notícia 
http://dx.doi.org/10.5902/1984686X37804

No momento da notícia, eu não recebi nada, só depois que eu vim conhecer o grupo que participo (P3).

No momento da notícia também nenhum apoio, tratamento normal (P5).

No momento da notícia não teve apoio nenhum não...mas logo que o médico falou também, ele já colocou a gente no grupo onde começou a ter tratamento para ela $(P 6)$

Não recebo apoio da rede pública (P7).

Segundo Cunha, Blascovi-Assis e Fiamenghi Jr (2010), o apoio aos familiares deve atender a todas as suas necessidades em cada momento. A mãe da criança com síndrome de Down necessita de subsídio para enfrentar esse período do nascimento. Para a família que recebe a notícia, deve receber orientação e apoio para cuidar do filho e para buscar qual o tratamento mais adequado. Porém para os pais P3, P5, P6 e P7, não houve esse apoio durante o momento da notícia.

Em relação a sugestões aos profissionais no momento da notícia aos pais, $\mathrm{P} 1 \mathrm{e}$ P9 apontaram não existir uma forma para se dar a notícia.

Eu acredito que não tenha uma forma de dar a notícia (P1).

Não sei se existe uma forma mais sutil de falar...A forma vai ser sempre essa olha seu filho vai nascer com alguma síndrome, síndrome de Down, ou qualquer outra (P9).

Para os pais P4 e P6, os profissionais poderiam dar a notícia de maneira mais cautelosa, com calma e carinho.

[...] dar com maior carinho, porque é uma notícia meio bruta, é bem complicada, eu acho que tem que ser bem sério, mas com carinho, com jeitinho (P4).

[...] eu acho que o cara grosso foi melhor...Eu acho que ele chegar e falar é melhor, não tem como ficar enrolando...Eu acho que o cara ter um pouco de mais calma, as vezes tem muitas mães que rejeitam, acho que para isso eles deveriam estudar um jeito melhor de falar (P6).

De acordo com Brunhara e Petean (1999), no momento da notícia aos pais, é importante que os profissionais da saúde tenham uma linguagem mais adequada, oferecendo a eles informações mais claras, objetivas e atualizadas. Não é necessário falar sobre prognóstico nesse momento e é de suma relevância, que eles deem tempo para que os pais consigam absorver as informações recebidas e fazerem as suas perguntas, a fim de esclarecer todas as dúvidas.

Para P2, a notícia poderia ser dada com referências a socialização das crianças com SD. 
http://dx.doi.org/10.5902/1984686X37804

Acho que seria mais a socialização, porque hoje ainda tem pessoas que discriminam (P2).

O participante P3 voltou-se para a visão médica, conforme ilustra seu relato a seguir

[...] para o médico também é complicado, porque eu já conversei com outros médicos referente a isso e todos eles, foi unânime, todos disseram, que quando eles têm isso em mãos, qual a sensação, também é de chorar, que eles também compartilham a dor com o paciente.

Para o participante P5, eles receberam a notícia muito rapidamente.

Nós descobrimos bem de supetão, eu falaria, cuide, porque não tem coisa melhor no mundo.

O participante P8 relatou que os médicos poderiam informar os familiares sobre a SD de forma mais popular e menos científica.

Vamos dizer assim, dar uma explicação menos cientifica e mais popular sobre o que é a síndrome de Down, porque ele deu a informação, vamos dizer assim, clara, mas eu que tive que correr atrás de algumas coisas, para saber exatamente o que era a síndrome (P8).

Para o P10, os médicos não conhecem sobre a síndrome.

Os profissionais são leigos quanto a síndrome, eles acham que não vão falar, andar, etc. (P10)

De acordo com os relatos, muitos pais acham que os profissionais da saúde não estão preparados para dar a notícia da SD aos familiares, pois fazem o uso da fala científica ao invés da popular, para melhor compreensão dos pais, dão as notícias de forma fria, quando poderiam ser mais cautelosos e defensivos.

\section{Considerações finais}

Podemos apontar, a partir desse estudo, que foi possível analisar e descrever as reações dos pais das crianças com SD, diante da notícia do diagnóstico da síndrome e quais foram os apoios recebidos para os cuidados dos filhos.

Em relação às entrevistas realizadas com os pais, pode-se verificar que no quesito maneira como a notícia da síndrome de Down foi dada, nove pais receberam após o nascimento da criança e apenas um pai recebeu a notícia durante a gestação.

Para mudanças na maneira como receberam a notícia, sete pais não mudariam a forma como foi dada, um pai voltou seu pensamento para uma visão médica, expondo que para o profissional da saúde, também é complicado dar a notícia, por isso que muitas vezes 
http://dx.doi.org/10.5902/1984686X37804

transmitem a notícia e vão embora, para não demonstrar sua fraqueza frente aos familiares e dois mudariam, relatando que os médicos poderiam ser sutis e que se soubessem durante a gestação, poderiam se preparar melhor.

Sobre conhecimentos atuais sobre a síndrome de Down, oito pais tiveram seus conhecimentos ampliados após o nascimento, pois começaram a frequentar grupos de apoios e a pesquisar na internet e apenas dois pais continuaram com os mesmos conhecimentos que tinham antes do filho com SD, pois já conheciam pelo menos uma pessoa com a síndrome.

Para a adaptação da dinâmica da família ao nascimento da criança com síndrome de Down, oito pais relataram algumas mudanças, como a esposa parar de trabalhar, a rotina de profissionais atendendo seus filhos, entre outras, dois pais disseram não necessitar quaisquer mudanças.

Em relação ao apoio para cuidados, metade dos pais recebeu algum apoio financeiro e a outra metade não recebeu nenhum apoio financeiro. Para o apoio recebido no momento da notícia, seis pais receberam algum tipo de ajuda, sendo a maior parte deles, por familiares e amigos e quatro pais não receberam nenhum apoio.

No quesito dar sugestões aos profissionais no momento da notícia de ter um filho com síndrome de Down, as respostas foram bem divergentes, pois dois pais disseram não existir uma forma correta para se dar a notícia, dois pais falaram que seria melhor se os médicos fossem mais cautelosos, mais cuidados e carinhosos, um pai queria que o profissional referenciasse a socialização da criança, um pai voltou seu pensamento para a visão médica, relatando o lado complicado para o médico transmitir essa notícia aos familiares, um pai falou que recebeu a notícia de supetão e que dessa forma foi melhor e um pai falou que os médicos parecem não saber sobre a síndrome de Down.

Uma dificuldade encontrada para a realização desta pesquisa foi encontrar um dia e horário que menos atrapalhasse a rotina das famílias. Nas outras questões os pais foram receptivos para participar do trabalho, respondiam as questões com muita sinceridade e sempre conversando além delas com a pesquisadora, tentando expor suas opiniões e ideias ou até mesmo quando tinham dúvidas.

O estudo mostrou que o momento da notícia precisa ser reavaliado pelos profissionais e que as intervenções devem focar nas crianças e nas famílias. Além disso, também revelou que as famílias conseguem se adaptar à nova realidade e que tal fato pode ter relação a frequentarem um grupo de apoio. 
http://dx.doi.org/10.5902/1984686X37804

A partir deste trabalho foi possível verificar sugestão para pesquisas futuras como, por exemplo, envolvimento paterno na rotina dos filhos com SD.

É importante ressaltar que há uma escassez de trabalhos voltados para os questionamentos dos pais (homens), pois sempre visam pesquisar e questionar as mães em relação aos seus filhos com deficiência.

\section{Referências}

BENCZIK, E. B. P., A importância da figura paterna para o desenvolvimento infantil. Rev. psicopedag., São Paulo, v. 28, n.85, p. 67-75. 2011. Disponível em:

http://pepsic.bvsalud.org/scielo.php?script=sci_arttext\&pid=S0103-84862011000100007. Acesso em: set. 2017.

BOLSANELLO, M. A. Interação mãe-filho portador de deficiência: concepções e modo de atuação dos profissionais em estimulação precoce. 1998. 156 f. Tese (Doutorado em Psicologia escolar e do desenvolvimento humano) - Departamento de Psicologia, Universidade de São Paulo, São Paulo, 1998.

CUNHA, A. M. F. V.; BLASCOVI-ASSIS, S. M.; FIAMENGHI JR, G. A. Impacto da notícia da síndrome de Down para os pais: histórias de vida. Rev. Ciênc. Saúd. Coletiv., v. 15, n. 2, p. 445-451, 2010. Disponível em:

http://www.scielosp.org/scielo.php?script=sci_abstract\&pid=S1413-

$81232010000200021 \&$ Ing=e. Acesso em: set. 2017.

DESSEN, M. A., \& BRAZ, M. P. Rede social de apoio durante transições familiares decorrentes do nascimento de filhos. Psicologia: Teoria e Pesquisa, v. 16, n. 3, p. 221231, 2000. Disponível em:

http://www.unifra.br/pos/saudecoletiva/downloads/Fam\%C3\%ADlias_e_rede_de_apoio.pd f. Acesso em: set. 2017.

GLAT, R. O papel da família na integração do portador de deficiência. Rev. Bras.

Educação Especial, v. 2, n. 4, p. 111-118, 1996. Disponível em:

http://www.abpee.net/homepageabpee04_06/artigos_em_pdf/revista4numero1pdf/r4_art0 9.pdf. Acesso em: set. 2017.

HENN, C. G.; PICCININI, C. A.; GARCIAS, G. L. A família no contexto da Síndrome de Down: revisando a literatura. Rev. Psicol. Estud., Maringá, v. 13, n. 3, p. 485-493, jul./set. 2008. Disponível em: http://www.scielo.br/scielo.php?pid=S1413-

73722008000300009\&script=sci_abstract\&tlng=pt. Acesso em: set. 2017.

LAMB, M. E. (1997). Fathers and child development: An introductory overwiew and guide. In M. E. Lamb (Org.), The role of the father in child development (pp.1-18). New York: Wiley.

LAMB, M. E., BILLINGS, L. A. L. (1997). Fathers of Children with Special Needs. Em M. E. Lamb (Ed.), The role of the father in child development (pp. 179-190). New York: John Wiley \& Sons. 
http://dx.doi.org/10.5902/1984686X37804

LAMB, M. E., et. al. (1985). Paternal behavior in humans. American Zoologist, 25, 883894.

MONDARDO, A.E., VALENTINA, D.D. Psicoterapia infantil: ilustrando a importância do vínculo materno para o desenvolvimento da criança. Psicol Reflex Crit. 1998;11(3):62130. Disponível em: http://www.scielo.br/scielo.php?pid=S0102-

$79721998000300018 \&$ script=sci_abstract\&tIng=pt. Acesso em: set. 2017.

SILVA, N. C. B.; AIELLO, A. L. R. Análise descritiva do pai da criança com deficiência mental. Estud. Psicol., São Carlos, v. 26, n. 4, p. 493 - 503, out/dez. 2009. Disponível em: http://www.scielo.br/scielo.php?script=sci_abstract\&pid=S0103-

166X2009000400010\&lng=pt\&tlng=pt. Acesso em: set. 2017.

SILVA, N. L. P.; DESSEN, M. A. Síndrome de Down: etiologia, caracterização e impacto na família. Interação em Psicologia, v. 6, n. 2, p. 167-176. 2002. Disponível em: http://revistas.ufpr.br/psicologia/article/viewFile/3304/2648-. Acesso em: set. 2017.

SOUZA, L. G. A.; BOEMER, M. R. O ser-com o filho com deficiência mental: alguns desvelamentos. Paidéia. v. 13, n. 26, p. 209-219. 2003. Disponível em:

http://www.scielo.br/scielo.php?pid=S0103-

863X2003000300010\&script=sci_abstract\&tIng=pt. Acesso em: set. 2017.

VENDRUSCULO, L. E. B. A descoberta da deficiência do filho: o luto e a elaboração dos pais. 2014. 34 f. Trabalho de Conclusão de Curso (Especialização) - Departamento de Humanidades e Educação, Universidade Regional do Noroeste do Estado do Rio Grande do Sul, ljuí, 2014.

\title{
Notas
}

\begin{abstract}
${ }^{1}$ A estimulação/intervenção precoce constitui-se em um programa de atendimento, inserido na Educação Especial, que busca especialmente promover o desenvolvimento de crianças com deficiências, nos primeiros anos de vida, mas notadamente dos zero aos três anos de idade (BOLSANELLO, 1998).
\end{abstract} International (CC BY-NC 4.0) 